\title{
Prevalence of Mycobacterium bovis in some cattle breeds in the aids era: An abattoir survey in Ogun State, Nigeria \\ ${ }^{1}$ Oyekunle, M.A. and ${ }^{2}$ Talabi, A.O. \\ ${ }^{1}$ Department of Veterinary Microbiology and Parasitology, ${ }^{2}$ Department of Veterinary Medicine and Surgery, College of Veterinary Medicine, Federal University of Agriculture, Abeokuta, Nigeria \\ E-mail: maoyekunle@yahoo.co.uk
}

\begin{abstract}
Eight breeds of cattle totalling 15520 heads and comprising of 3784 bulls and 11736 cows were examined during slaughter in the two largest abattoirs in Ogun State, Nigeria between January and December, 2007. Samples of lung, liver, spleen, kidney, udder, skin and pleural lymph nodes with gross lesions suspected to be those of tuberculosis were obtained from the slaughtered animals. Each of the samples was processed according to the standard method and thereafter stained by Ziehl-Neelsen's technique and was microscopically examined for acid fast organisms. Samples containing acid fast bacilli were cultured on Lowenstein-Jensen (LJ) medium with pyruvate or glycerol. M. bovis was identified by growth rate, pigment production, colony and cell morphology and biochemical characteristics. A total of 41 heads of cattle comprising of 9 bulls and 32 cows from 7 breeds were positive for $M$. bovis. No isolate of $M$. bovis was obtained from Keteku breed and no seasonal distribution of the organism was observed. Among the organs with lesions, the lung had the highest number (18) of M. bovis. The number of White Fulani cattle with M. bovis was highest (13) among the breeds examined.
\end{abstract}

Keywords: Prevalence, Mycobacterium bovis, Cattle, Abattoir, Ogun State

\section{Introduction}

Some members of the Genus Mycobacterium cause tuberculosis in human and animals. Although there are over 80 named species of mycobacteria only members of the Mycobacterium tuberculosis complex cause tuberculosis in man and animals (McFadden, 1992). This complex includes Mycobacterium tuberculosis (M. tuberculosis), Mycobacterium bovis (M. bovis), Mycobacterium africanum (M. africanum) and others (Grage, 2002).

According to Grage (2002) members of the complex are closely related species which on generic analysis are variant of single species. Record of tuberculosis as contained in the Assyrian King Assanbanipal's library (668-626BC) had it that $M$. bovis had been causing tuberculosis in animals before invading human (Esse, 2001). According to history, it was after domestication of cattle that there was evidence of tuberculosis in human through milk ingestion (Esse, 2001).

Bovine tuberculosis caused by M. bovis occurs mainly via the respiratory route leading to a primary disease of the lungs but can be disseminated to cause lesions in other organs. Bovine tuberculosis can be transmitted to human through respiratory route, consumption of unpasteurized infected milk, meat and meat products (Radostits et al., 2007). Punctured wounds and cuts of butchers and other related workers can also be contaminated by bovine tuberculosis organs.

By 2003, not less than 17 million people are 
reported to be infected with tuberculosis (WHO, 2003) and these may represent either reactivation or new infections and the former is thought to be more common. It is estimated that almost one third of the world's population have latent tuberculosis infection (Sepkowitz et al., 1994). It has also been estimated that progression from latent tuberculosis infection to clinical disease occurs in $5 \%$ of non-HIV infected individuals (Allen et al., 1992) but this increases to $30 \%$ in HIV infected persons (McFadden, 1992). Persons co-infected with HIV and tuberculosis have an estimated $10 \%$ annual risk of developing fatal tuberculosis (Allen et al., 1992). Whereas human tuberculosis caused by $M$. bovis have been eradicated in most of the developed world (McFadden, 1992), $M$. bovis accounted for $20 \%$ of cases in Nigeria (Garba et al., 2004). Since M. bovis infection in human is likely to be acquired through animal sources, control of the disease in cattle should form a major part of the tuberculosis eradication programme. A pre-requisite to the control/eradication of tuberculosis is its surveillance among domestic and wild animals. In this study, we reported the prevalence of $M$. bovis among some cattle breeds slaughtered for human consumption in Ogun State, Nigeria.

\section{Materials and Methods \\ Collection of Samples}

Samples suspected to be tuberculosis lesions comprising of lung, liver, kidney, spleen, skin, peritoneal lymph node and udder were collected from a total of fifteen thousand, five hundred and twenty (15520) heads of cattle from eight breeds of cattle (Table 1) during slaughter in the two largest abattoirs in Ogun State, Nigeria. These abattoirs are those located in Lanfewa, Abeokuta and Ijebu-Igbo. The samples which were collected between January and
December 2007 were transported in ice pack to the laboratory immediately after collection and stored under refrigeration at $4^{\circ} \mathrm{C}$ until processed.

Laboratory examination of the samples Processing of the samples: Each sample was ground in sterile mortar and pestle with sterile sand. The homogenized sample was then treated with $10 \mathrm{ml}$ of $4 \%$ sodium hydroxide containing phenol red $(15 \mathrm{mg} /$ litre) with constant shaking for 20 minutes at room temperature. This was centrifuged at $300 \mathrm{rpm}$ for 15 minutes. The supernatant was poured off into dettol ${ }^{\circledR}$ in water (disinfectant) and the sediment restored to neural $\mathrm{pH}$ by adding $25 \%$ hydrochloric acid $(\mathrm{HCl})$ drop by drop.

Direct examination of the sample: Smears of sediments from each of the samples were made on microscopic glass slides and stained by Ziehl-Neelsen's technique (Barrow and Felthan, 1993) for presence of acid fast organisms.

Isolation and cultural procedures: Sediment from the sample was mixed well and $0.1 \mathrm{ml}$ from it was inoculated onto triplicate slants of LJ medium with pyruvate or with glycerol. These slants were incubated overnight at room temperature in a horizontal position, then at $37^{\circ} \mathrm{C}$ in upright position and examined weekly for 8 to 12 weeks. When there was growth, the colony was dropped on a microscope glass slide by means of a coarse inoculating needle with a flat end. A smear was made and stained by Ziehl Neelsen's technique. The stained smear was then examined under an oil immersion objective (x100) of a light microscope (Olympus, Germany).

Test to detect pigment production by the isolates: This was carried out by subculturing the isolate into two tubes of LJ medium. One tube was incubated in light 
and the second wrapped in aluminium foil and incubated in darkness all at $37^{\circ} \mathrm{C}$.

Biochemical tests: Production of niacin, nitrate reductase and catalase production by the isolates were determined according to the methods of Barrow and Felthan (1993).

\section{Results}

All the smears prepared directly from the suspected samples and stained by ZiehlNeelsen's stain technique were positive for acid fast bacilli (AFB). The colonies which are dry, sparse appeared within 15-19 days post incubation. The cells are small, slender and acid fast. No pigment was produced in light and darkness. The isolates did not produce niacin, catalase and nitrate reductase and were therefore identified as M. bovis. The M. bovis was not isolated from Keteku of all the 8 breeds of cattle that were investigated. All the other 7 breeds were positive for $M$. bovis with the prevalence $(0.1 \%)$ lowest in Red Bororo and highest $(0.5 \%)$ in Adamawa breed (Table 1).

The total number of Nigerian cattle with $M$. bovis was $41(0.26 \%)$ comprising of 32 $(0.21 \%)$ cows and $9(0.06 \%)$ bulls (Table 2 ). The number of cows with $M$. bovis was significantly higher $(\mathrm{P}<0.05)$ than the bulls (Table 2).

In those breeds of cattle that carried $M$. bovis, the organism was disseminated in not less than two organs (Table 3 ) with the lung (18 cases) being the most affected organs followed by the pleura ( 7 cases). More cow than the bull lungs (14 vs 4) were affected. The udder accounted for 4 cases. Only the cow pleural lymph nodes carried $M$. bovis. Except for the month of March, when no cases were encountered, the monthly occurrence of the organism in cattle did not show any consistent pattern in relation to the season of the year. The usual climate pattern in Nigeria is that the dry season occurs in November through to March while the rainy season is between April and October every year. However, the prevalence of $M$. bovis in cattle was highest in January which is within the dry season period (Table 4). The mean monthly occurrence of $M$. bovis is significantly

Table 1: Status of $M$. bovis in Nigerian breeds of cattle

\begin{tabular}{llllll}
\hline Breed & $\begin{array}{l}\text { No } \\
\text { examined }\end{array}$ & Bull & Cow & $\begin{array}{l}\text { No (\%) with } \\
\text { M. bovis }\end{array}$ & Mean $\left( \pm \mathrm{SE}^{*}\right)$ \\
\hline Ndama & 997 & 251 & 746 & $03(0.30)$ & $0.25^{\mathrm{bc}}(0.13)$ \\
Muturu & 1321 & 285 & 1036 & $04(0.30)$ & $0.33^{\mathrm{bc}}(0.14)$ \\
Kuri & 1230 & 385 & 845 & $05(0.41)$ & $0.50^{\mathrm{b}}(0.19)$ \\
White Fulani & 3626 & 859 & 2767 & $13(0.36)$ & $1.08^{\mathrm{a}}(0.23)$ \\
Red Bororo & 4011 & 881 & 3130 & $04(0.10)$ & $0.33^{\mathrm{bc}}(0.14)$ \\
Sokoto Gudali & 2186 & 640 & 1546 & $07(0.32)$ & $0.58^{\mathrm{b}}(0.15)$ \\
Adamawa & 980 & 211 & 769 & $05(0.51)$ & $0.42^{\mathrm{bc}}(0.15)$ \\
Keteku & 1169 & 272 & 897 & $0(0.00)$ & $0.00^{\mathrm{c}}(0.00)$ \\
\hline & & & & & \\
Total & 15520 & 3784 & 11736 & $41(0.2$ & \\
\hline
\end{tabular}

*mean of occurrence of $M$. bovis in breeds of cattle

a,b,c means along the same column having different superscript are different $(\mathrm{P}<0.05)$ 
Prevalence of Mycobacterium bovis in some cattle breeds in the aids era

Table 2: Sex distribution of $M$. bovis in Nigerian breeds of cattle

\begin{tabular}{|c|c|c|c|c|c|c|c|c|c|c|c|}
\hline \multirow[t]{2}{*}{ Sex } & \multicolumn{8}{|c|}{ Number of Animals with $M$. bovis } & \multirow{2}{*}{\multicolumn{2}{|c|}{$\begin{array}{l}\mathrm{n} \\
\left( \pm \mathrm{SEM}^{*}\right.\end{array}$}} & Mean \\
\hline & $\mathrm{Nd}$ & Mt & $\mathrm{Kr}$ & WF & $\mathrm{RB}$ & $\mathrm{SG}$ & Ad & $\mathrm{Kt}$ & & & \\
\hline Male & 1 & 1 & 2 & 2 & 1 & 2 & 0 & 0 & $\begin{array}{l}9 \\
\left(0.06^{\circ}\right.\end{array}$ & $\begin{array}{l}8 \\
(0.30)^{b}\end{array}$ & 1.13 \\
\hline
\end{tabular}

$\begin{array}{llllllllll}\text { Female } 2 & 3 & 3 & 11 & 3 & 5 & 5 & 0 & 32 & 8 \\ (0.21 \%)(1.15)^{\mathrm{a}}\end{array}$

\begin{tabular}{llllllllll}
\hline Total & 3 & 4 & 5 & 13 & 4 & 7 & 5 & 0 & 41
\end{tabular}

*mean of sex occurrence of $M$. bovis in breeds of cattle

${ }^{\mathrm{a}, \mathrm{b}}$ means along the same column having different superscript are different $(\mathrm{P}<0.05)$

\begin{tabular}{|c|c|c|c|}
\hline $\mathrm{Nd}=\mathrm{Ndama}$ & $\mathrm{Mt}=$ Muturu & $\mathrm{Kr}=\mathrm{Kuri}$ & $\mathrm{WF}=$ White Fulani \\
\hline $\begin{array}{l}\mathrm{RB}=\text { Red Bororo } \\
\mathrm{N}=\mathrm{No} \text { of breeds }\end{array}$ & $\mathrm{SG}=$ Sokoto Gudali $\mathrm{Ad}=$ Adamawa & $\mathrm{Kt}=\mathrm{Kete} \mathrm{ku}$ & \\
\hline
\end{tabular}

higher $(\mathrm{P}<0.05)$ in White Fulani than in the other breeds. The mean monthly occurrence is significantly lower $(\mathrm{P}<0.05)$ in Ndama, Muturu, Red Bororo and Adamawa than in the other breeds that were examined (Table 4).

\section{Discussion}

The detection of AFB by acid fast staining directly from the samples suggests that these samples carry approximately not less than $10^{4}$ bacilli per gramme of the sample (Gording and Slutkin, 1990). The identification of the isolates as M. bovis was based on the cultural characteristics, cell

Table 3: Dissemination of $M$. bovis in organs of Nigerian breeds of cattle

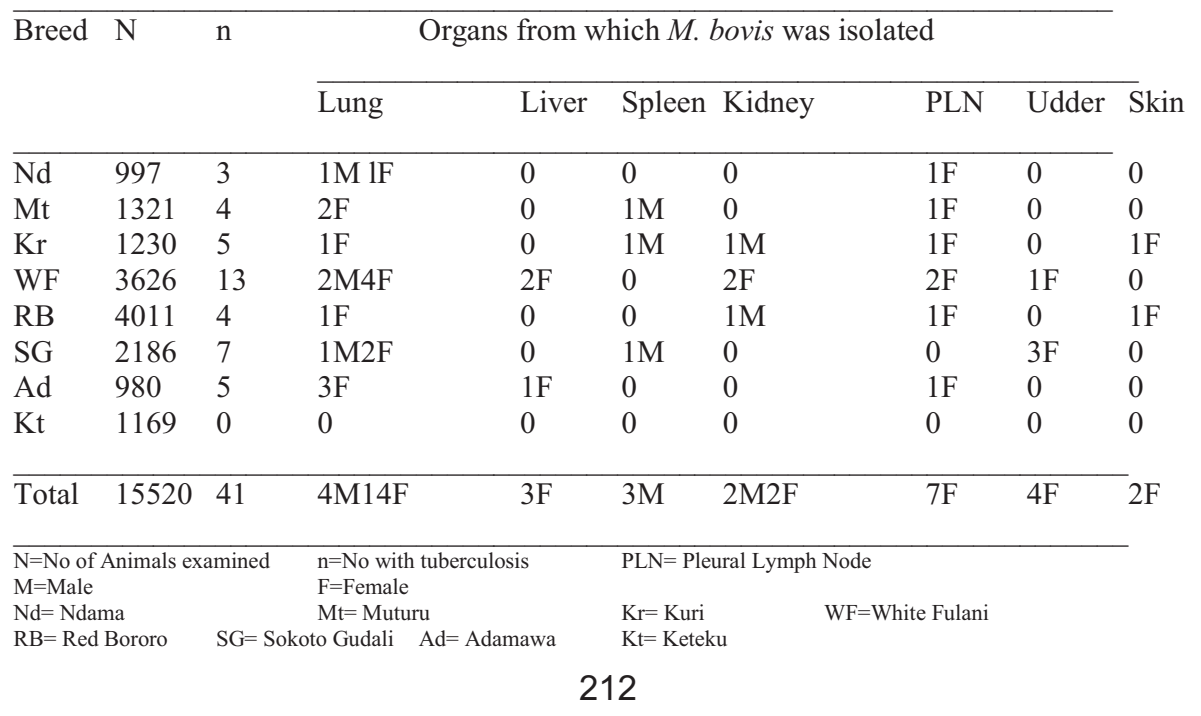


Oyekunle and Talabi

Table 4: Prevalence of $M$. bovis in slaughtered cattle in Abeokuta and Ijebu Igbo abattoirs

\begin{tabular}{|c|c|c|c|c|c|c|c|c|c|c|}
\hline \multirow[t]{2}{*}{ Month } & \multirow[t]{2}{*}{$\mathrm{N}$} & \multirow[t]{2}{*}{$\mathrm{n}$} & \multicolumn{8}{|c|}{ Monthly occurrence of $M$. bovis } \\
\hline & & & $\mathrm{Nd}$ & Mt & $\mathrm{Kr}$ & WF & $\mathrm{RB}$ & SG & Ad & $\mathrm{Kt}$ \\
\hline January 1508 & 5 & $0 / 94$ & $1 / 127$ & $0 / 51$ & $1 / 361$ & $1 / 446$ & $1 / 211$ & $1 / 87$ & $0 / 131$ & \\
\hline February & 1337 & 2 & $0 / 84$ & $0 / 113$ & $0 / 45$ & $1 / 320$ & $0 / 397$ & $0 / 186$ & $1 / 78$ & $0 / 114$ \\
\hline March & 1423 & 0 & $0 / 89$ & $0 / 120$ & $0 / 48$ & $0 / 342$ & $0 / 421$ & $0 / 200$ & $0 / 81$ & $0 / 122$ \\
\hline April & 722 & 2 & $0 / 33$ & $0 / 118$ & $1 / 107$ & $1 / 116$ & $0 / 71$ & $0 / 145$ & $0 / 89$ & $0 / 43$ \\
\hline May & 1665 & 6 & $1 / 101$ & $1 / 108$ & $1 / 206$ & $1 / 355$ & $1 / 420$ & $1 / 216$ & $0 / 119$ & $0 / 140$ \\
\hline June & 1974 & 10 & $1 / 151$ & $1 / 186$ & $2 / 243$ & $3 / 450$ & $1 / 350$ & $1 / 227$ & $1 / 169$ & 0/196 \\
\hline July & 1284 & 5 & $0 / 77$ & $0 / 83$ & $1 / 130$ & $2 / 360$ & $1 / 320$ & $1 / 140$ & $0 / 72$ & $0 / 102$ \\
\hline August & 1205 & 4 & $1 / 84$ & $0 / 80$ & $0 / 246$ & $1 / 257$ & $0 / 250$ & $1 / 258$ & $1 / 24$ & $0 / 06$ \\
\hline September & 188 & 1 & $0 / 14$ & $0 / 20$ & $0 / 07$ & $0 / 51$ & $0 / 61$ & $0 / 04$ & $1 / 13$ & $0 / 18$ \\
\hline October 1265 & 2 & $0 / 73$ & $1 / 98$ & $0 / 39$ & $1 / 280$ & $0 / 447$ & $0 / 161$ & $0 / 67$ & $0 / 100$ & \\
\hline November & 1496 & 2 & $0 / 94$ & $0 / 127$ & $0 / 51$ & $1 / 358$ & $0 / 442$ & $1 / 209$ & $0 / 85$ & $0 / 130$ \\
\hline December & 1453 & 2 & $0 / 103$ & $0 / 141$ & $0 / 57$ & $1 / 376$ & $0 / 386$ & $1 / 229$ & $0 / 96$ & $0 / 67$ \\
\hline Total & 15520 & 41 & $3 / 997$ & $4 / 1321$ & $5 / 1230$ & $13 / 362$ & $6,4 / 401$ & $1,7 / 218$ & $6,5 / 980$ & $0 / 1169$ \\
\hline Mean $\left( \pm \mathrm{SE}^{*}\right)$ & & & $\begin{array}{l}0.25^{b c} \\
(0.13)\end{array}$ & $\begin{array}{l}0.33^{b c} \\
(0.14)\end{array}$ & $\begin{array}{l}0.50^{\mathrm{b}} \\
(0.19)\end{array}$ & $\begin{array}{l}1.08^{\mathrm{a}} \\
(0.23)\end{array}$ & $\begin{array}{l}0.33^{b c} \\
(0.14)\end{array}$ & $\begin{array}{l}0.58^{b} \\
(0.15)\end{array}$ & $\begin{array}{l}0.42^{b c} \\
(0.15)\end{array}$ & $\begin{array}{l}2.00^{\mathrm{c}} \\
(0.00)\end{array}$ \\
\hline
\end{tabular}

*mean of monthly occurrence of $M$. bovis in breeds of cattle

a,b,c means along the same column having different \pm superscripts are different $(\mathrm{P}<0.05)$

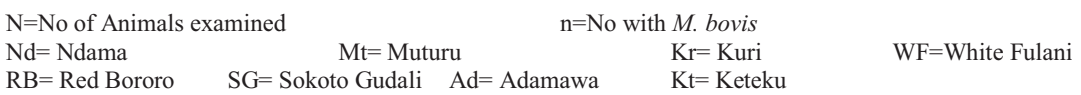

morphology and staining reaction and the results of the biochemical tests that were performed.

In the absence of more rapid methods (Shawar et al., 1993) culture, staining and biochemical tests are approximately equal in sensitivity in the identification of Mycobacteria (Kolo, 1991).

Although the percentage of carriers of $M$. bovis among the breeds of cattle examined in this study was low $(0.26 \%)$ the spread of the organism among them was wide as seven out of 8 breeds carried M. bovis (Table 1). The absence of M. bovis in the Keteku can be assumed to be due to the natural resistance of the breed to many infections but this cannot be substantiated in the present study. The distribution of $M$. bovis in many body organs of the affected animals lends credence to the usual characteristics of $M$. bovis infection. This facilitates the transmission of the infection through ingestion of the affected organs and products (milk) or by inhalation through respiratory discharge of $M$. bovis from infected animals (Radostits et al., 2007). Involvement of $M$. bovis in human infection has been reported in many countries of the world (Griffith, 1937; Christensen et al., 1981; Silber et al., 1987) including Nigeria (Idigbe et al., 1986; Kolo, 1991). Apart from the practice of close association between man and its livestock in some parts of Nigeria, ingestion of infected or contaminated meat product (suya), raw milk and some local milk products (fura) can facilitate the transmission of M. bovis to humans. Most of the slaughtered cattle in 
Nigeria are derived from those reared by the herdsmen.

These tuberculosis reservoir cattle are extensively reared by the herdsmen who move from one state to the other in Nigeria. Furthermore, these herdsmen are known to be closely associated with their animals (Garba, 2002). All these practice enhance spread of the organism in the environment and its transmission to the herdsmen.

In the developing countries like Nigeria, tuberculosis is spreading rapidly because of many reasons such as neglect by government in finding of cases and treatment, increasing urbanization with people living in overcrowded houses in densely populated communities. Other reasons include increasing poverty with malnutrition and increasing air pollution from infected animals and humans. It is speculated that about $75 \%$ of the world tuberculosis cases occur in developing countries (WHO, 2003). For effective control of bovine tuberculosis in Nigeria, education of those at risk of the disease is important. The key facts to be understood include how

i. bovine tuberculosis is caused and spread between animals and humans

ii. poor ventilation and over overcrowding hasten the spread of the disease.

iii. poor hygiene and malnutrition enhance the spread of the disease.

iv. effective cooking of food from animal sources will reduce or eliminate bovine tuberculosis.

\section{References}

Allen, S., B at ungwanaya, J., Keriikowske, K., Lifson, A.R., Wolf, W., Granich, R., Taelman, H., Van de Perre, P., Serufilira, A., Bogeeris, J., Slutkin, C. and Hopewell, P. 1992. Two year incidence of tuberculosis in cohorts of HIV-infected and uninfected urban Rwandan women. Am. Rev. Respir. Dis. 146: 1439-1444.

Barrow, G.T. and Felthan, R.K.A. 1993. Cowan and Steel Manual for the identification of Medical Bacteria, $3^{\text {rd }}$ ed., Cambridge University Press.

Christensen, E.E., Dietz, G.W., Ahn, C.H., Chapman, J.J., Murry, R.C., Anderson, J. and Hurst, G.A. 1981. Initial Roentegenographic manifestations of pulmonary Mycobacterium tuberculosis, $M$. kausasii and $M$. intracellularis infections. Chest, 80: 132-136.

Esse, M. 2001. Tuberculosis in Animal and man. In: Zoonoses, Animal Diseases that affect man. A publication of the Christian Veterinary Mission, edited by Goodman, D.E., p. 13-22.

Garba, H.S. 2002. Epidemiological study of Tuberculosis in Livestock and man in Sokoto, Nigeria. Unpublished Ph.D Thesis submitted to Usman Danfodiyo University, Sokoto, Nigeria.

Garba, H.S., Ahmed, H. and Galadima, M. 2004. Characterization of Mycobacterium isolated from cases of tuberculosis in human in Sokoto. Nig. Vet. J. 25 (1): 30-34.

Gording, F. and Slutkin, G. 1990. The validity of acid fast smears in the diagnosis of tuberculosis. Ach. Pathol. Lab. Med. 114:1025-1027.

Grage, J.M. 2002. Mycobacterium. In: Medical Microbiology: A guide to microbial infections, pathogenesis, immunity, laboratory diagnosis and control, $16^{\text {th }}$ ed., edited by Greenwood, D., Slack, R.C.B. and Peutherer, J.F. Elsevier Science Ltd., ChurchillLivingstone.

Griffith, A.S. 1937. Bovine Tuberculosis in man. Tubercle, 18: 529-543.

Idigbe, E.O., Anyim, C.E. and 
Onwuejekwe, D.L. 1986. Human pulmonary infections with bovine and atypical mycobacteria infections in Lagos, Nigeria. J. Trop. Med. Hyg. 7: 384-387.

Kolo, J. 1991. Bacteriologic and drug sensitivity studies of mycobacteria isolated from tuberculosis patients and their close contacts in Ahmadu Bello University, Zaria. A. Ph.D. Dissertation submitted to Ahmadu Bello University, Zaria, Nigeria.

McFadden, J. 1992. Mycobacteria. In: Encyclopaedia of Microbiology, Vol. 3 , Acad. Press, Inc. Harconal Brace. p. 203-214.

Radostits, O.M., Gay, C.C., Hinchcliff, K.W. and Constable, P.D. 2007. Veterinary Medicine: A textbook of the Diseases of Cattle, Sheep, Pigs, Goats and Horses. $10^{\text {th }}$ ed., Saunders Elsevier, Spain. p.1007-1014.

Sepkowitz, K.A., Teizak, E.E., Recaide, S., Armstrong, D. and the New York
City Area Tuberculosis Working Group 1994. Tuberculosis susceptibility trends in New York City, 1987-1991. Clin. Infect. Dis., 18: 755-759.

Shawar, R.M., El-Zaatari, F.A.K., Nataraj $A$. and Clarridge, J.E.1993. Detection of Mycobacterium tuberculosis in clinical samples by two-step polymerase chain reaction and nonisotopic hybridization methods. J. Clin. Microbiol, 31: 61-65.

Silber, P., James, A.W., Harden, J.W., Gregory, H.J., Cutter, G.R. and Michael, M.H. 1987. A study of the cost of tuberculosis contact investigation related to nontuberculosis mycobacterial isolation in Jetterson county, Alabama. Public Hlth. 101:297-304.

WHO 2003. Tuberculosis. In: State of the World's Vaccines and Immunization, Revised edition. p. 61-62.

Received: $15 / 11 / 12$

Accepted: 26/0/2/13 